STUDI

FRANCESI

\section{Studi Francesi}

Rivista quadrimestrale fondata da Franco Simone

170 (LVII | II) | 2013

Varia

\title{
Eva Sansavior, Maryse Condé and the Space of Literature
}

\section{Claudia Mansueto}

\section{Q OpenEdition}

1 Journals

\section{Édition électronique}

URL : https://journals.openedition.org/studifrancesi/3249

DOI : 10.4000/studifrancesi.3249

ISSN : 2421-5856

Éditeur

Rosenberg \& Sellier

\section{Édition imprimée}

Date de publication : 1 juillet 2013

Pagination : 498-499

ISSN : 0039-2944

\section{Référence électronique}

Claudia Mansueto, «Eva Sansavior, Maryse Condé and the Space of Literature », Studi Francesi [En ligne], 170 (LVII | II) | 2013, mis en ligne le 30 novembre 2015, consulté le 02 février 2023. URL : http:// journals.openedition.org/studifrancesi/3249; DOI : https://doi.org/10.4000/studifrancesi.3249

Ce document a été généré automatiquement le 2 février 2023.

\section{(c) $(1) \&$}

Creative Commons - Attribution - Pas d'Utilisation Commerciale - Pas de Modification 4.0 International - CC BY-NC-ND 4.0

https://creativecommons.org/licenses/by-nc-nd/4.0/ 


\title{
Eva Sansavior, Maryse Condé and the Space of Literature
}

\author{
Claudia Mansueto
}

\section{RÉFÉRENCE}

EVA SANSAVIOR, Maryse Condé and the Space of Literature, London, Legenda, 2012, pp. 137.

1 Consacré à Maryse Condé, à ses œuvres et à ses batailles, l'essai d'Eva Sansavior analyse les défis et les conquêtes idéologiques de l'intellectuelle guadeloupéenne. Envahie par un «nomadic impulse» (p. 1) sauvage et créatif, Condé (dé)construit l'idée d'identité et, pour utiliser les mots de Sansavior, «re-maps» (p. 3) son itinéraire littéraire. Femme de la différence, errante «au-dehors et au-dedans» (p. 2), Condé refuse les catégories, les définitions, «the homogeneous commun consensus» (p. 5): l'intellectuelle guadeloupéenne défend sa pluralité identitaire, son horizon existentiel «multidirectional» (p. 11). Créole, francophone, anglophone, Condé est l'écrivaine du nonlieu, de la résistance a-territoriale: constamment en révolte, elle défend le conflit, le «reframing» (p. 5) incessant qui nous emmène à la découverte d'un univers existentiel indéfini, une totalité-monde rhizomique nourrie par «dissenting voices» (p. 17) inconnues. Toujours engagée, l'écrivaine guadeloupéenne défend son activité politique, son projet de «relationships between identity politics, anti-colonial resistance [and] cultural and literary politics» (p. 17): indissociables, les «notions of politics, literature and space» (p. 18) nourrissent l'humus créatif de Maryse Condé et définissent son itinéraire idéologique.

2 L'essai d'Eva Sansavior comprend six chapitres: Performing "the Personal» in the Interview (pp. 22-36) qui «considers the implications of Condé's marked use of interviews» (p. 18); Re-writing the Journey to Africa or finding the wrong ancestors in "En attendant le Bonheur" (pp. 37-52) qui analyse les réactions littéraires déterminées par la diffusion de l'œuvre de Condé en France, en Amérique et dans sa terre natale; Voice, Irony and History in "Moi Tituba, sorcière... Noire de Salem" (pp. 53-66) qui réfléchit sur les «re-formulations of 
questions of voice, history, agency and community» (p. 18); Autobiography and Reading in "Le Coeur à rire et à pleurer: Contes vrais de mon enfance" (pp. 67-81) qui explore ce que Sansavior définit «the complex blurring between fictional and autobiographical elements» (p. 19) dans l'œuvre de Condé; Literature, Art and Identity Politics in "Les Derniers Rois mages" (pp. 82-98) qui analyse les profondeurs culturelles et identitaires du milieu existentiel de Condé et On the Creative Uses of Gaps. (Re)-imagining Identity in "Desirada" (pp. 99-118) qui «examines the role of immigration» (p. 18) à travers une réflexion critique sur la problématique de la globalisation et de la «black identity» (p. 18).

Soutenue par un riche corpus bibliographique, Eva Sansavior présente au grand public un personnage littéraire kaléidoscopique, pluriel: Maryse Condé est une écrivaine, une voix solitaire et dissonante, une maquisarde djebarienne qui témoigne sa diffraction, qui défend son autonomie. Concentrée sur l'enthousiasme militant qui anime les œuvres de Condé, Sansavior souligne l'anticonformisme idéologique de l'intellectuelle guadeloupéenne: orientée par un engagement politique souterrain, la littérature est, avant tout, expression de liberté, de créativité. Pont idéal entre Sartre et Maurice Blanchot, Condé propose «the reformulation of literary engagement» (p. 120) pour théoriser la réalisation d'un espace littéraire créatif et critique, intime et polyphonique à la fois. Fascinée par «the process of renewal» (p. 122) de l'écrivaine francophone, Sansavior présente un essai original, une étude complexe qui ouvre «the space of literature» (p. 122) à la solidarité et à l'énergie de l'imaginaire. 